\title{
Applications of Parallel Synthesis to Lead Optimization
}

\begin{abstract}
Michael Altorfera ${ }^{\mathrm{a}}$, Philipp Ermert ${ }^{\mathrm{a}}$, Jürg Fässlera ${ }^{\mathrm{a}}$, Saleem Farooq ${ }^{\mathrm{b}}$, Elke Hillesheim ${ }^{\mathrm{b}}$, André Jeanguenat ${ }^{b}$, Klaus Klumpp ${ }^{c}$, Peter Maienfisch ${ }^{b}$, Joseph A. Martin ${ }^{c}$, John H. Merrett ${ }^{c}$, Kevin E.B. Parkes ${ }^{c}$, Jean-Pierre Obrecht ${ }^{a}$, Thomas Pitterna ${ }^{b}$, and Daniel Obrecht ${ }^{a *}$
\end{abstract}

\section{Dedicated to Prof. Dr. A. Vasella on the occasion of his 60th birthday}

\begin{abstract}
Parallel synthesis of focused compound libraries for hit confirmation and lead optimization are certainly important drivers for shortening the lead discovery phase in the pharmaceutical and crop protection industries. In this article we show with permission of Roche and Syngenta three real case studies where Polyphor synthesized focused libraries for lead validation and optimization using high-throughput parallel synthesis and purification techniques. The three examples differ significantly in the synthetic strategies which were employed as well as in the chemical complexity of the final products. A multigeneration approach towards insecticidal triazines, the application of a sequential three-component reaction towards insecticidal and fungicidal thiazoles and finally a multistep synthesis approach of advanced building blocks followed by a two-step final derivatization towards novel antiviral N-hydroxy-indolin-2-ones are presented. In all cases 100-200 analogues were synthesized using parallel synthesis in solution followed by purification of the final products by parallel flash or high-throughput (unattended) HPLC (coupled to MS) within four months. Promising biological results were obtained in all three cases.
\end{abstract}

Keywords: High-throughput purification · N-hydroxy-indolin-2-ones as influenza endonuclease inhibitors . Insecticidal and fungicidal thiazoles · Insecticidal triazines · Lead validation and optimization . Parallel synthesis

\section{Introduction}

Since 1996 Polyphor has supported the pharmaceutical and chemical industry in its efforts to identify and optimize lead compounds [1].

The process usually starts with highthroughput screening (HTS) of a substance library of small molecules (MW < 600) on a new target as schematically shown in Fig. 1. In a second step, focused libraries are used to optimize the lead structures identified in the HTS. Polyphor offers a

Correspondence: Dr. D. Obrecht

Tel: + +41614869898

Fax: +41614869899

E-Mail: daniel.obrecht@polyphor.com

apolyphor AG

Gewerbestrasse 14

$\mathrm{CH}-4123$ Allschwil

byngenta Crop Protection AG

Research and Technology,

$\mathrm{CH}-4002$ Basel

CRoche Discovery Welwyn

40 Broadwater Road

Welwyn Garden City

Herts, AL BAY, UK substance library consisting of $15^{\prime} 000$ small molecules for general and random screening. $15^{\prime} 000$ is a comparably small number, however, this library is derived from 63 drug-like scaffolds and is thus very diverse and a good complement to the pharma industry's internal depositories. As a consequence of HTS the pharmaceutical and crop protection companies have now identified many hits. Hit-to-lead and lead optimization has now become the bottle neck and thus a growing area for outsourcing and an opportunity for start-up companies.

However, only a small number of companies has overcome the entry barrier to this market, since it needs time and persistence to gain the confidence and trust of life science companies, to prove the capability to solve challenging chemical problems efficiently and to keep to the time lines. Because most projects are highly confidential, it is difficult to demonstrate a track record. We would like to take this opportunity to present, with the permission of Syngenta and Roche, three real case studies of focused libraries.
In addition these examples show three different types of parallel synthesis approaches [2] that Polyphor has successfully applied.

a) multigeneration approaches;

b) application of sequential multi-component reactions and

c) multistep synthesis of advanced building blocks followed by one or two step parallel conversion into final products.

\section{Multigeneration Approach Towards Insecticidal Triazines [3]}

In collaboration with André Jeanguenat and Saleem Farooq; Syngenta Crop Protection AG, Research and Technology, CH-4002 Basel

\subsection{Introduction}

In a random screening program, 1,2,4triazines such as $\mathbf{1}$ and $\mathbf{2}$ were identified as novel fungicidal lead compounds (Fig. 2). They displayed an interesting activity against species such as Phytophthora infestans (late blight), Pyrenophora teres (net 
blotch) and Septoria nodum (glume blotch) with a new and unknown mode of action. Substituting the triazine position 3 with an appropriate phenyl group gave a new class of compounds (e.g. 3) with a very potent insecticidal activity, mainly against lepidoptera, as well as against some sucking insects.

\subsection{Target and Design}

To evaluate the potential of these new classes of compounds, a library of unsymmetrical triazines of general formulae $\mathbf{I}$ and II was designed as shown in Fig. 3. In order to determine which substitution pattern was most important for biological activity, it was of particular interest to design a selective synthesis for 3,6-disubstituted and for 3,5-disubstituted triazines.

\subsection{Synthesis}

Based on the library design we devised a multigeneration approach for $\mathrm{R}^{1}=\mathrm{SMe}$; $\mathrm{SOMe} ; \mathrm{SO}_{2} \mathrm{Me}$ and $\mathrm{OMe}$ as all intermediate products were part of the general library as shown in Scheme 1. Condensation of $(S)$-methyl-isothiosemicarbazide 4 [4] with glyoxals 6 gave separable mixtures of the two triazines 7 and $\mathbf{8}$ ( 7 being generally the major product) in $60-80 \%$ yield. Glyoxals 6 were obtained from the corresponding methyl ketones 5 by oxidation with $\mathrm{SeO}_{2}$ in a mixture of dioxane and water at $80{ }^{\circ} \mathrm{C}$. Conversion of $\mathbf{7}$ and $\mathbf{8}$ into sulfoxides $\mathbf{9}$ and $\mathbf{1 1}$ and sulfones $\mathbf{1 0}$ and $\mathbf{1 2}$, and subsequent transformation into products $\mathbf{1 3}$ and $\mathbf{1 4}$ was performed using standard procedures starting from roughly $300 \mathrm{mg}$ of $\mathbf{7}$ and $\mathbf{8}$.

Scheme 2 shows the synthesis of the parent triazines of type $\mathbf{I}$ and $\mathbf{I I}$ with $\mathrm{R}^{1}$ : 2,4- $(\mathrm{Cl})_{2}-\mathrm{C}_{6} \mathrm{H}_{3}$ and 2,6-(F) $)_{2}-\mathrm{C}_{6} \mathrm{H}_{3}$. Reaction of amidrazones $\mathbf{1 5}$ with glyoxals $\mathbf{6}$ gave again mixtures of triazines I and II $(\sim 1: 9)$ which were separated by flash chromatography.

In order to circumvent problems of separation and low yield of isomer I, we investigated new regioselective approaches to triazines I. Literature reports [5] suggested that oximes 16 might be suitable precursors for the regioselective synthesis of $\mathbf{I}$. Oximes 16 could be efficiently synthesized by using a trans-oximation reaction with acetone oxime in dioxane and an aqueous $\mathrm{NaH}_{2} \mathrm{PO}_{4}$ solution as a mild acid catalyst. After screening numerous reaction conditions in parallel format, we found that mixing 15 and 16 in $4 \mathrm{~N} \mathrm{HCl} /$ dioxane (4-5 equiv.) in n-butanol at $80{ }^{\circ} \mathrm{C}$ gave $75-85 \%$ of triazines I. Reaction of $\mathbf{1 7}$ and $\mathbf{1 8}$ gave $\mathbf{1 9}(82 \%)$ as shown in Scheme 3.

In summary, a 180-member library of trazines of type I and II was synthesized within four months using the synthetic

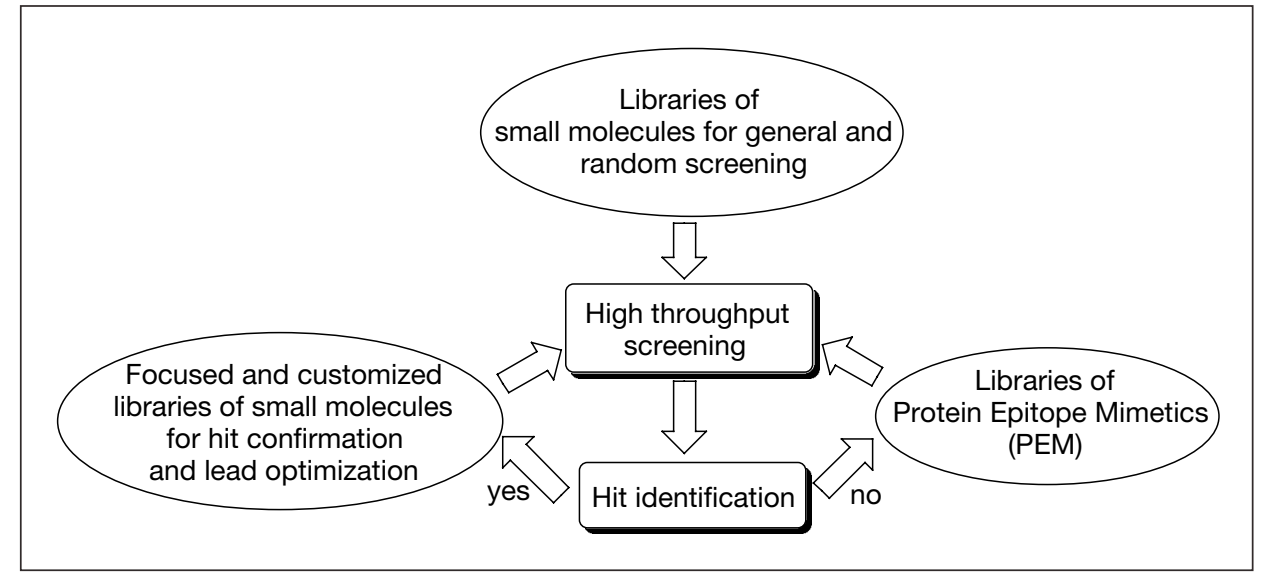

Fig. 1. Polyphor libraries in the lead finding and optimization process [1]

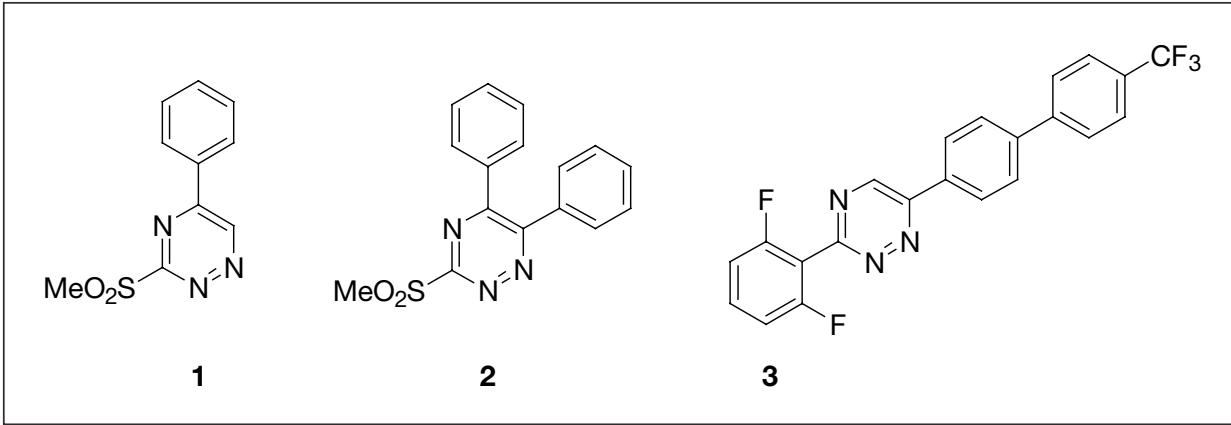

Fig. 2. Initial hits based on the triazine scaffold
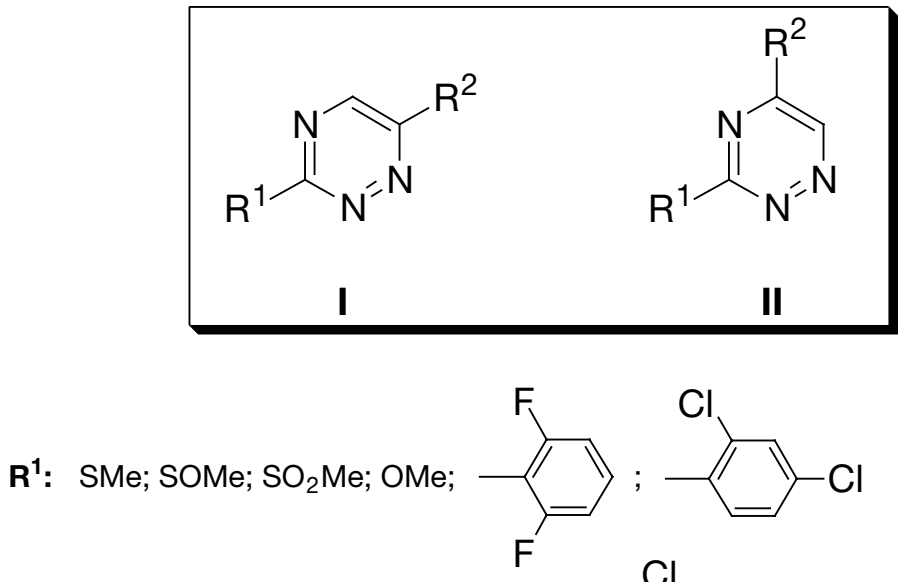

$\mathbf{R}^{2}$
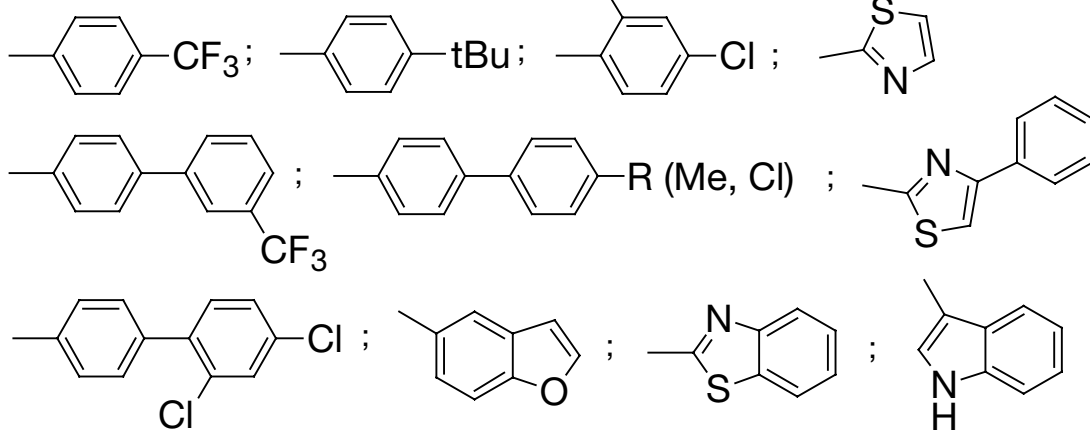<smiles>Cc1ccc2occc2c1</smiles><smiles>Cc1nc2ccccc2s1</smiles><smiles>Cc1c[nH]c2ccccc12</smiles>

Fig. 3. Design of triazine libraries I and II 


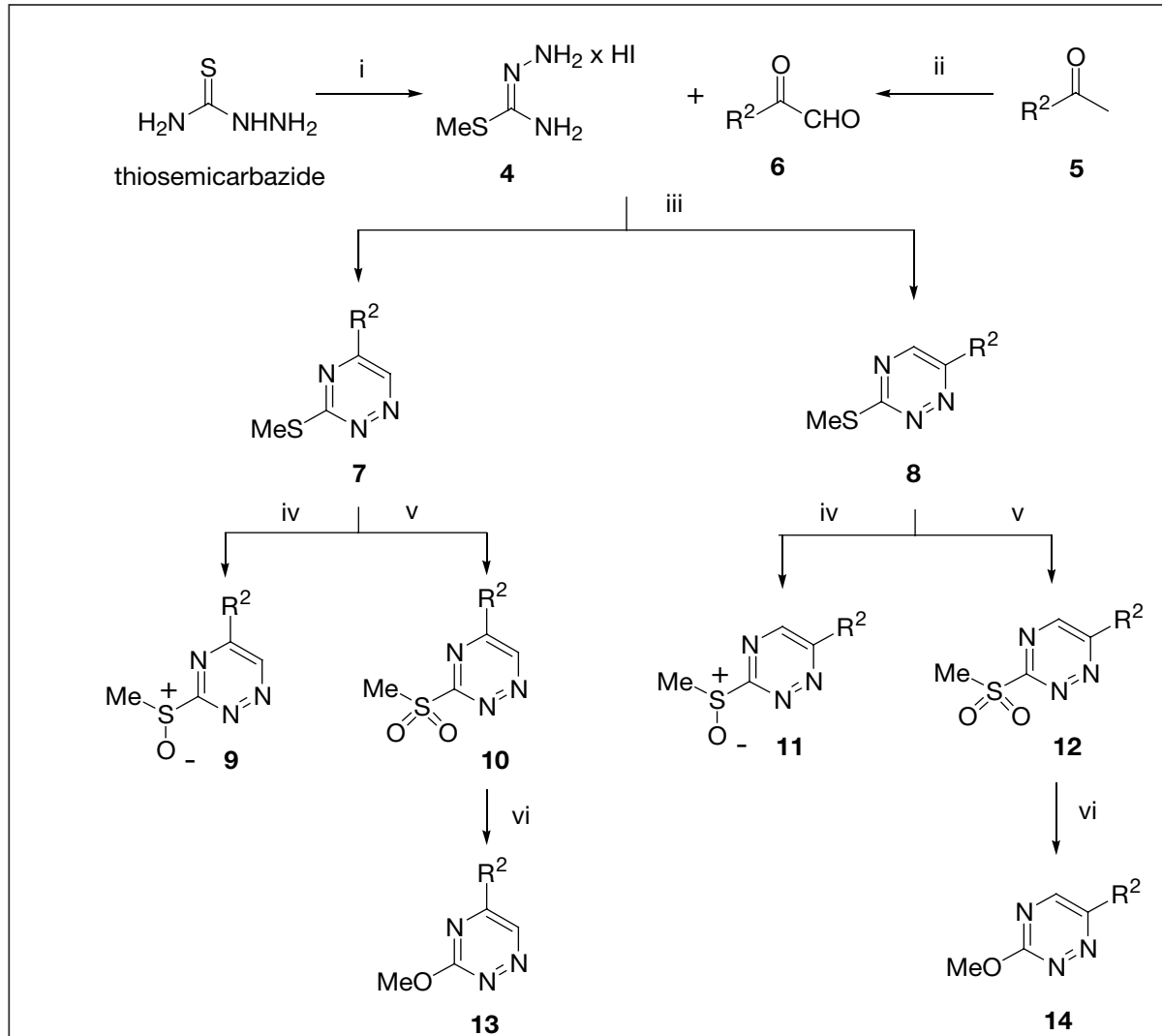

i: Mel, dioxane; ii: $\mathrm{SeO}_{2}$, dioxane/ $\mathrm{H}_{2} \mathrm{O}, 80^{\circ} \mathrm{C}$; iii: DIEA, DMF or $\mathrm{CH}_{2} \mathrm{Cl}_{2}$; then separation; iv: mCPBA (1.1 equiv.), $\mathrm{NaOAc}, \mathrm{CH}_{2} \mathrm{Cl}_{2} ;$ v: mCPBA (2.5 equiv.), $\mathrm{NaOAc}, \mathrm{CH}_{2} \mathrm{Cl}_{2}$; vi: $\mathrm{NaOMe}$, THF

Scheme 1

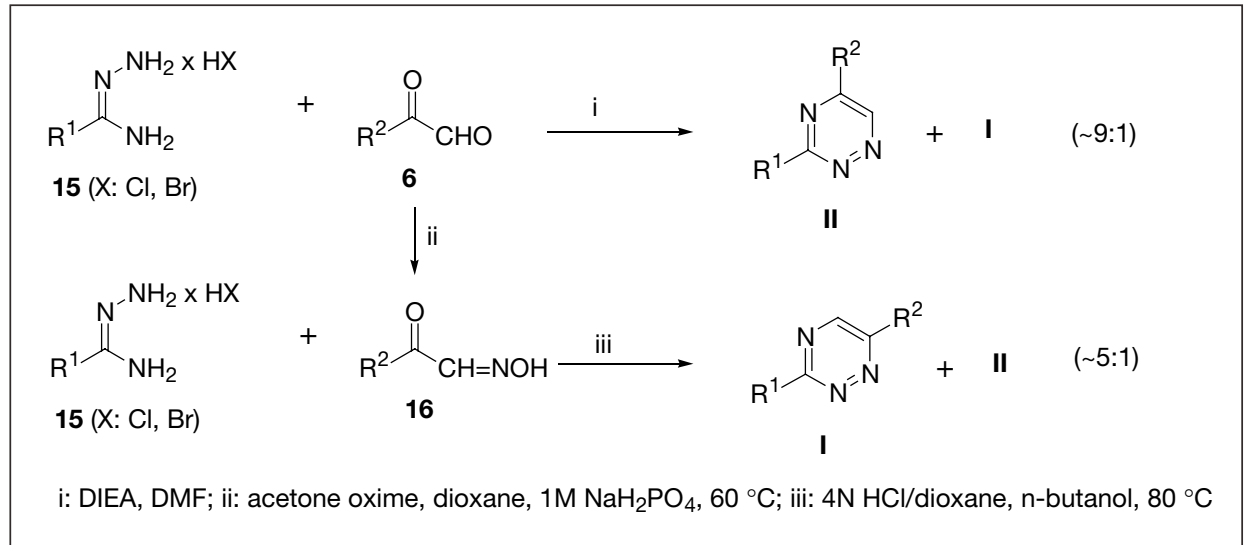

Scheme 2.

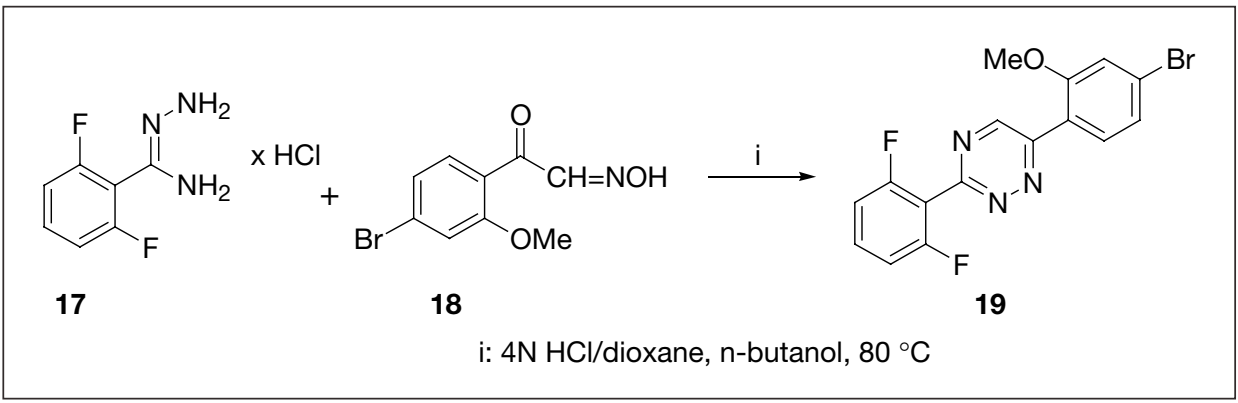

Scheme 3. approaches described in this chapter. In addition the stage was set for more focused triazine libraries of type I which were biologically more interesting than the parent triazine II

\subsection{Biological Results and Conclusion}

In the fungicidal screening, compounds with a substituent in position 3 , such as $\mathrm{S}(\mathrm{O})_{\mathrm{n}} \mathrm{Me}(\mathrm{n}=0,1,2)$ and $\mathrm{OMe}$, displayed some interesting activities. Main targets were oomycetes such as Phytophthora infestans (late blight), Plasmopora viticola (grape downy mildew), and Pythium ultimum (ashy stem blight) as well as Pyrenophora teres (net blotch) and Septoria (glume blotch). Among the compounds with insecticidal activity, 3,6-disubstituted triazines of type I displayed a very potent activity against key chewing insects such as Spodoptera littoralis (beet armyworm), Heliothis virescens (tobacco budworm), and Plutella xylostella (diamondback moth) and also against some sucking pests, at a level comparable to the best commercial standards.

Furthermore, this example shows that multigeneration approaches can be performed in parallel format if optimized reaction conditions can be applied. Thus the overall number of synthetic steps per library compound can be significantly reduced as compared to a linear approach.

\section{Insecticidal and Fungicidal Thiazoles Using a Novel Sequential Multicomponent Reaction [6]}

In collaboration with Elke Hillesheim, Thomas Pitterna, and Peter Maienfisch, Syngenta Crop Protection AG, Research and Technology, CH-4002 Basel

\subsection{Introduction}

In a random screening program, the N-thiazol-2-yl-benzamide $\mathbf{2 0}$ was identified as a novel insecticidal lead compound. Compound $\mathbf{2 0}$ as well as its chloro analogue 21 (Fig. 4) possess good activity against many chewing and sucking insects and are strong uncouplers of oxidative phosphorylation with $\mathrm{IC}_{50}$ values in the low $\mathrm{nM}$ range.

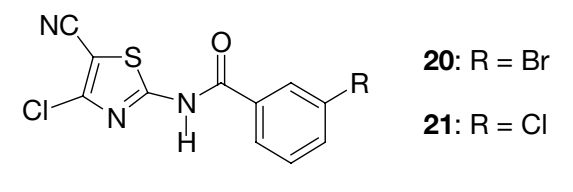

Fig. 4. Initial hits based on the aminothiazole scaffold 
To further exploit the potential of this chemical class, libraries of compounds of types III and IV (Fig. 5) were designed based on a novel sequential three component reaction [7] developed by Polyphor.

In library III, $\mathrm{R}^{1}$ comprised aromatic and heteroaromatic substituents as well as $\mathrm{CF}_{3}$, whereas in library $\mathbf{I V}, \mathrm{R}^{1}$ was chosen as $\mathrm{NH}_{2}$ (electron-donating group, $\mathrm{H}$-bond donor). In both libraries $\mathrm{E}$ (electron-withdrawing group) was selected from $\mathrm{CN}, \mathrm{CH}_{3} \mathrm{CO}, 2,4-(\mathrm{Cl})_{2} \mathrm{C}_{6} \mathrm{H}_{3} \mathrm{CO}, 4-\mathrm{NO}_{2}-$ $\mathrm{C}_{6} \mathrm{H}_{4} \mathrm{CO}, \mathrm{CF}_{3} \mathrm{CO}$ and $4-\mathrm{CF}_{3}-\mathrm{C}_{6} \mathrm{H}_{4} \mathrm{CO}$. For groups $\mathrm{Z}$ we chose $\mathrm{CO}, \mathrm{SO}_{2}$ and direct connection of the nitrogen to the 3-chlorophenyl group, and $\mathrm{R}^{2}$ was chosen from $\mathrm{Me}$ and $\mathrm{EtOCH}_{2}$ groups.

\subsection{Synthesis}

For the synthesis of the libraries III and IV we took advantage of a novel sequential three-component reaction starting from amidines $\mathbf{2 2}$ or isothiourea $\mathbf{2 5}$, isothiocyanates 23 and $\mathrm{ECH}_{2} \mathrm{X}(\mathbf{2 4}$, E: electronwithdrawing group) as shown in Scheme 4 Yields ranged from $40-80 \%$.

Scheme 5 shows a possible mechanism for the formation of thiazoles of type $\mathbf{2 7} \mathrm{via}$ intermediates $\mathbf{V}, \mathbf{V I}$ and VII. Thiouronium salt $\mathbf{2 5}$ is first reacted with isothiocyanates 23 in the presence of DIEA or DBU in DMF to form the reactive intermediates of type $\mathbf{V}$, which can be isolated if required or reacted in situ with $\mathbf{2 4}$ in the presence of a second equivalent of base. Alkylation proceeds most probably at the sulfur atom to form intermediates VI, which react via an intramolecular Knoevenagel-type condensation via intermediates VII to form after elimination of 1-mercapto-hexane products of type 27. Scheme 6 describes the three-component reaction of $\mathbf{2 2}$ or $\mathbf{2 5}$ with 2,4-dimethoxy-benzyl-isothiocyanate $\mathbf{2 8}$ and $\mathbf{2 4}$ to yield intermediate thiazoles 29. Thiazoles 29 were either treated with 3 -chlorobenzene sulfonyl chloride followed by removal of the 2,4-dimethoxy-benzyl group with trifluoroacetic acid in $\mathrm{CH}_{2} \mathrm{Cl}_{2}$ to yield sulfonamides $\mathbf{3 0}$ or treated with 3-chlorobenzoyl chloride followed by deprotection of the intermediates with trifluoroacetic acid in $\mathrm{CH}_{2} \mathrm{Cl}_{2}$ to yield amides 31 . These transformations were performed in parallel format with purification of $\mathbf{3 0}$ and 31. Overall yields were in the range of 40-70\%. Subsequent alkylation of $\mathbf{3 0}$ and 31 with either MeI or $\mathrm{ClCH}_{2} \mathrm{OEt}$ in DMF and $\mathrm{K}_{2} \mathrm{CO}_{3}$ gave products $\mathbf{3 2}$ and $\mathbf{3 3}$, which were again purified by parallel flash chromatography. A library of roughly $150 \mathrm{com}-$ pounds was prepared by Polyphor and screened by Syngenta.

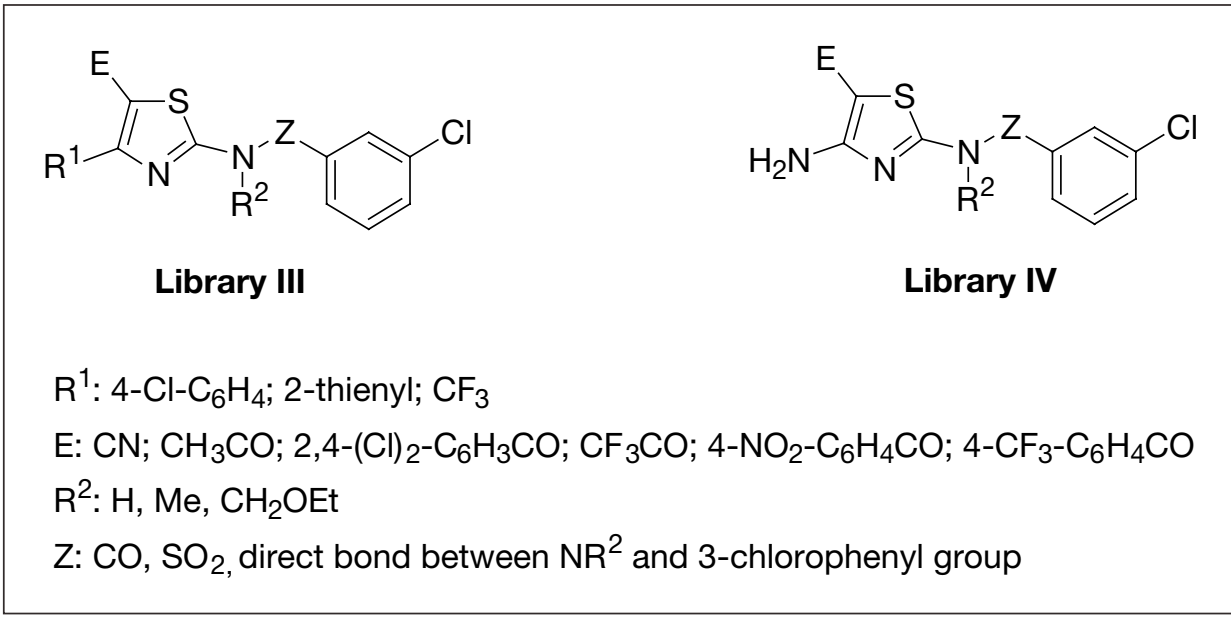

Fig. 5. Design of aminothiazole libraries III and IV

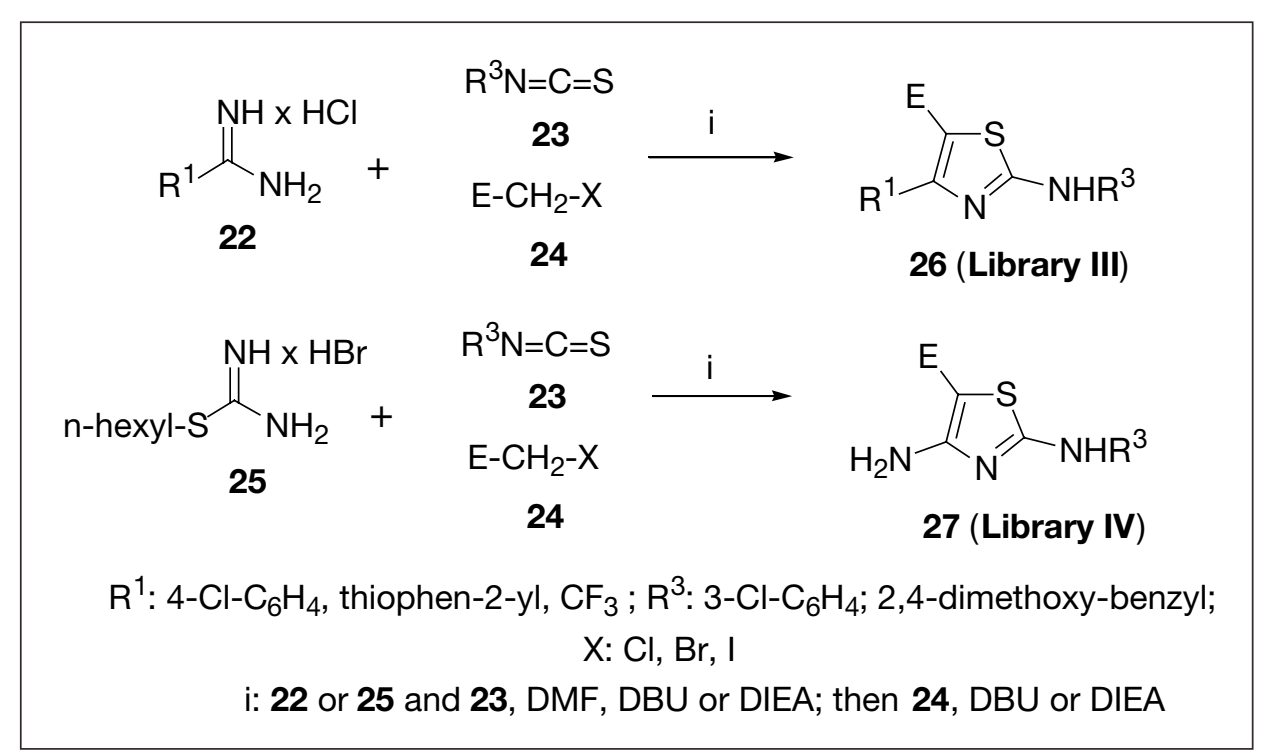

Scheme 4.

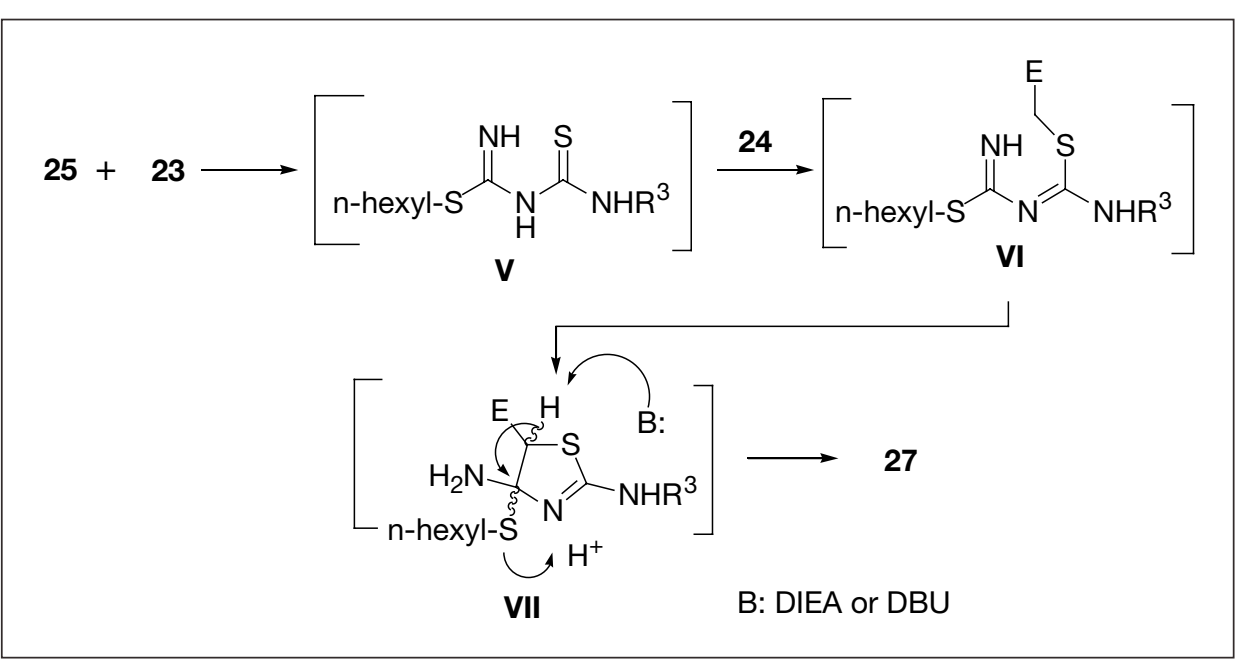

Scheme 5. 


\subsection{Biological Results and Conclusions}

The library was evaluated in a standard HTS screening for insecticidal, herbicidal and fungicidal activity. None of these compounds reached the insecticidal activity of the lead structures 20 and 21. However, some thiazoles of type III displayed interesting fungicidal (nine compounds) and herbicidal (three compounds) activity. The detected fungicidal activity was mainly on one pathogen, Pyricularia oryzae (rice blast), whereas herbicidal activity was observed on Stellaria media (common chickweed). The most potent compounds were those with $\mathrm{R}^{1}=\mathrm{CF}_{3}$ and $\mathrm{E}=\mathrm{CN}$, 4- $\mathrm{NO}_{2}$ $\mathrm{C}_{6} \mathrm{H}_{4}-\mathrm{CO}$ or $2,4-(\mathrm{Cl})_{2} \mathrm{C}_{6} \mathrm{H}_{3} \mathrm{CO}$. Among all compounds prepared, best activity was observed for thiazole 34 (Fig. 6).<smiles>N#Cc1sc(NC(=O)c2cccc(Cl)c2)nc1C(F)(F)F</smiles>

Fig. 6. Most active analogue 34

\section{Parallel Synthesis of a New Class of Influenza Endonuclease Inhibitors [8][9]}

In collaboration with K. Klumpp, J.A. Martin, J.H. Merrett and K.E.B. Parkes, Roche Discovery Welwyn, 40 Broadwater Road, Welwyn Garden City, Herts, AL7 3AY, UK

\subsection{Introduction}

Influenza virus infects an estimated 120 million people in US, Europe and Japan in a typical year. The influenza endonuclease is an attractive target for several reasons: a) It is a key component of the viral transcription mechanism, which has no cellular counterparts and should therefore provide a good potential for discovering selective, non-toxic drugs.

b) In contrast the neuraminidase inhibitors that do not prevent the formation of new virus particles, but interfere with virus release from host cells and are therefore virustatic, endonuclease inhibitors, due to the block of viral transcription, are expected to have a virucidal effect.

\subsection{Target Mechanism and Inhibitor Design}

Endonuclease of influenza RNA polymerase belongs to the group of phosphate-

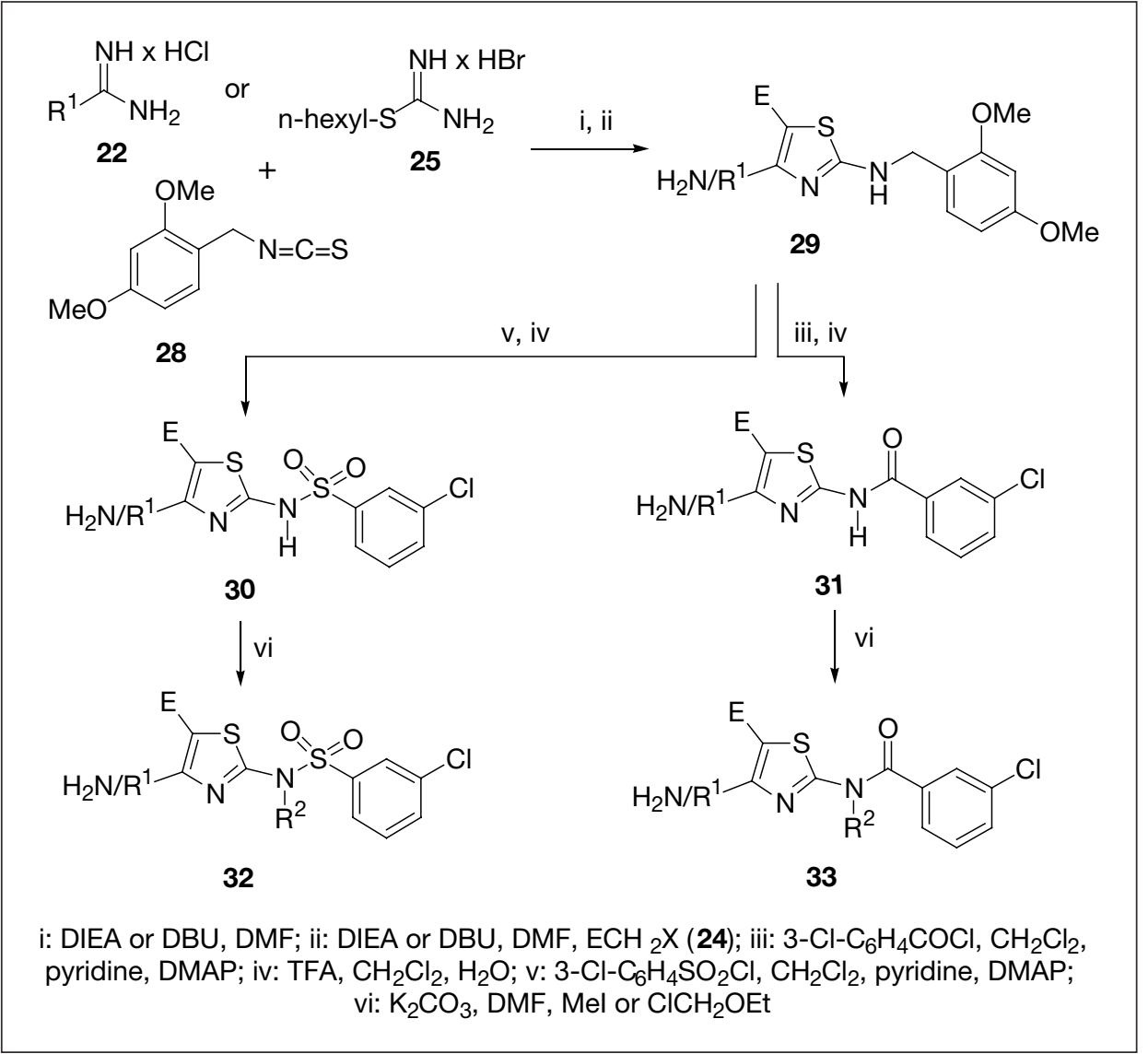

Scheme 6.

processing enzymes containing two divalent metal ions, particularly $\mathrm{Mn}^{2+}$ and $\mathrm{Mg}^{2+}$ ions.

HTS for endonuclease inhibitors gave rise to two different lead series belonging to the ketobutanoates of type $\mathbf{3 5}$ and the $N$-hydroxy-imides of type $\mathbf{3 6}$ as shown in Fig. 7. Both lead series are potential chelators of divalent cations. Based on these and further molecular modeling studies the Roche group proposed tetramic acid derivatives derived from $\mathrm{N}$-hydroxy-indolin2-ones of type VIII as a novel pharmacophore combining structural features of both the ketobutanoates $\mathbf{3 5}$ and the N-hydroxy-imides 36

Based on the general formula VIII, Polyphor proposed to synthesize three sublibraries 37, $\mathbf{3 8}$ and $\mathbf{3 9}$ as shown in Fig. 7. A literature review indicated that compounds of type 37-39 had not been synthesized before. As discussed with Roche we planned to have $\mathrm{R}^{1}$ as the low variation substituent $\left(\mathrm{R}^{1}\right.$ : Me, Et and $\left.\mathrm{Ph}\right)$ and $\mathrm{R}^{3}, \mathrm{R}^{4}$ and $\mathrm{R}^{5}$ as high variation substituents (typically 25 or 50 variations) as shown in Fig. 8.

\subsection{Synthesis}

We anticipated that N-hydroxy-indolin2-one derivatives VIII would offer several synthetic challenges especially in view of a parallel synthesis approach as indicated in Fig. 8:

- The $\beta$-ketoamide and hydroxamic acid groups are both acidic and potentially troublesome functional groups, for which suitable protection would be required.

- The final molecules would be highly polar and good isolation and purification methods would be required.

Fig. 9 shows that the three sub-libraries of type $\mathbf{3 7 ,} 38$ and $\mathbf{3 9}$ could be synthesized from a common precursor of type IX.

The synthesis of the key building blocks of type IX is shown in Schemes 7-10.

The synthesis started from commercial aniline derivative 40, which was Boc-protected to give $\mathbf{4 1}$ as shown in Scheme 7. Treatment of $\mathbf{4 1}$ with 2.2 equiv. of sodium dimethylmalonate in DMSO gave a high yield of the nucleophilic substitution product 42, which was saponified using aq. $2 \mathrm{~N} \mathrm{NaOH} / \mathrm{MeOH}$ at $80{ }^{\circ} \mathrm{C}$ to give after acidification the phenylacetic acid $\mathbf{4 3}$ in $60-70 \%$ overall yield from 40. In order to synthesize the whole library $50 \mathrm{~g}$ of acid 43 was required.

The conversion of $\mathbf{4 3}$ to $\mathbf{4 4}$ offered two major challenges:

a) Partial reduction of the nitro group into the corresponding hydroxylamine followed by cyclization to the N-hydroxyindolin-2-one. 


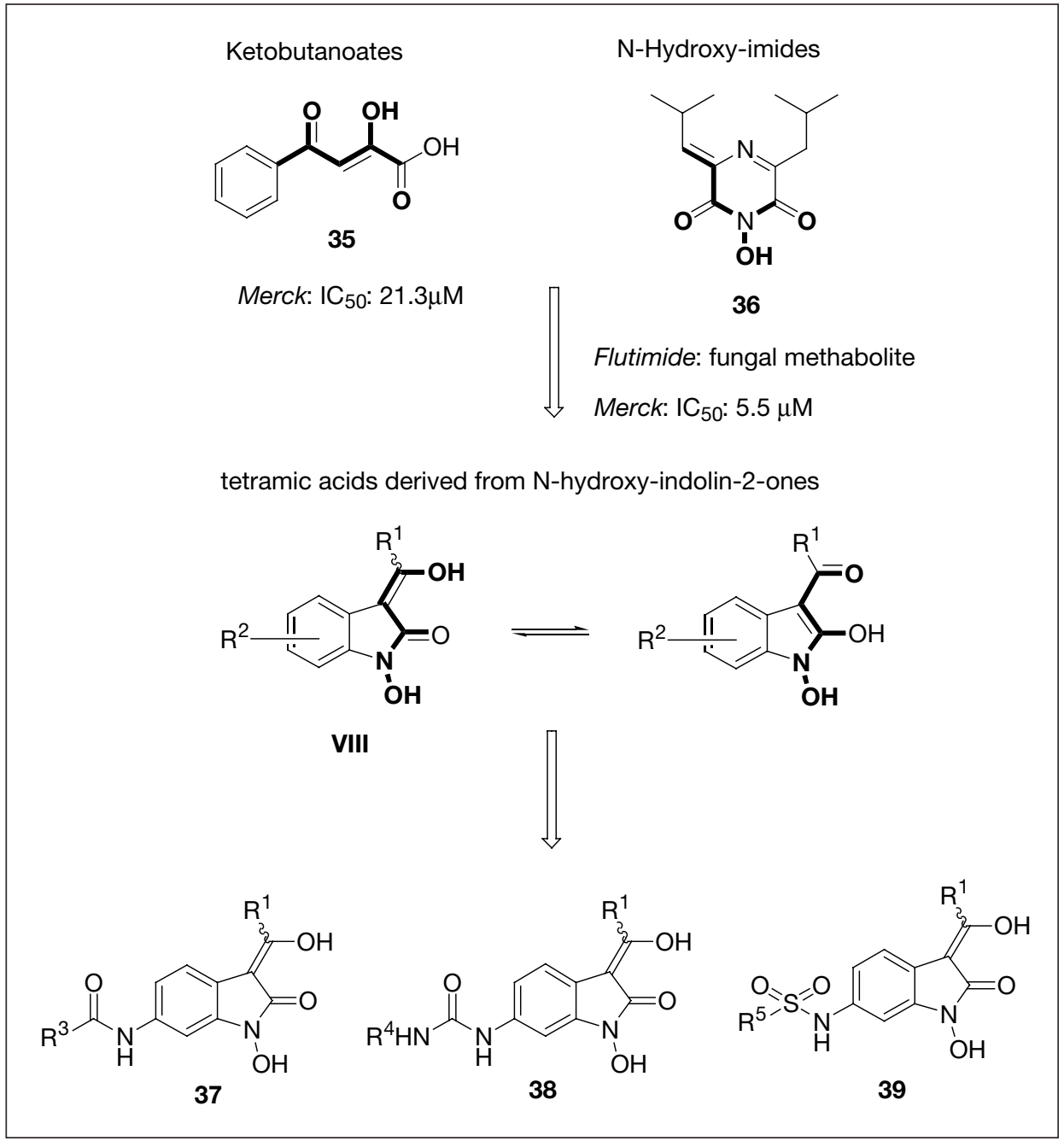

Fig. 7. Design of the N-hydroxy-indolin-2-one scaffold

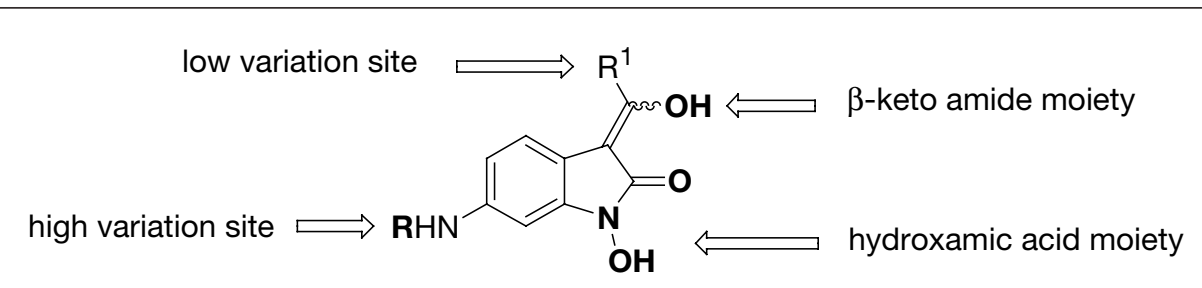

Fig. 8. Potential sites of variation in the N-hydroxy-indolin-2-one scaffold

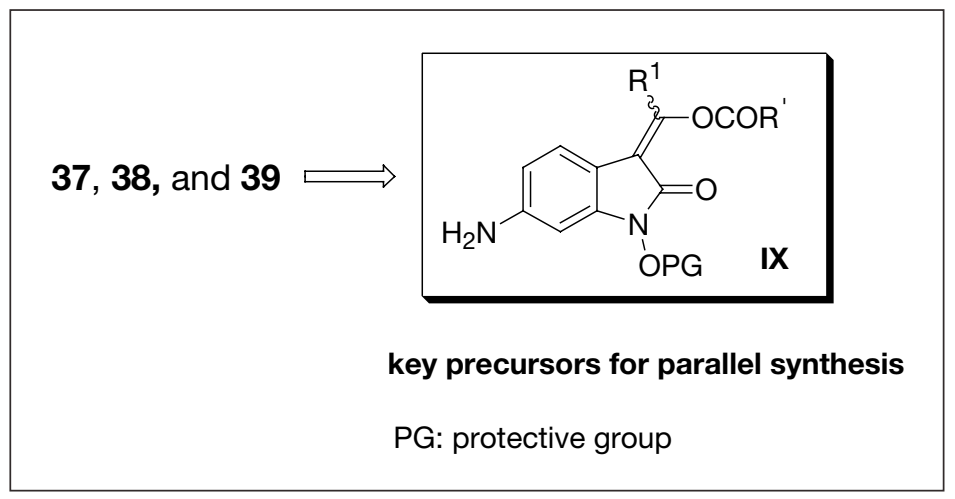

Fig. 9. Key precursors for parallel synthesis b) Identification of a suitable protective group for the hydroxamic acid group which would be stable enough for the subsequent steps and could be removed quantitatively in the last step.

Among the methods known for the reduction of aromatic nitro groups into a hydroxylamine group we focused on the hydrogenation procedure described by Kende [10] using Pt/C and DMSO. After screening several reaction conditions we found that using a solvent mixture of EtOH/THF 2:1 and DMSO in the presence of $\mathrm{Pt} / \mathrm{C}$ and $\mathrm{H}_{2}$, followed by cyclization using acetic acid gave the desired $\mathrm{N}$-hydroxy-indolin-2-one derivative in roughly $65 \%$ yield along with $5-10 \%$ of the corresponding lactam, obtained from overreduction of the hydroxyl amine to the aniline, as a mixture of solids of low solubility which was difficult to further purify. This mixture was treated directly with pivaloyl chloride in $\mathrm{CH}_{2} \mathrm{Cl}_{2}$ in the presence of diisopropylethylamine (DIEA) to give $\mathbf{4 4}$ in high yield after chromatography on $\mathrm{SiO}_{2}$ along with the lactam. The pivaloyl group not only proved to be an excellent protective group for the hydroxamic acid moiety but also made all derivatives highly soluble and amenable to chromatographic purification. With the key building block 44 in hand we tried to introduce the $\beta$-ketoamide group as shown in Scheme 8.

In a first series of experiments we attempted the conversion of $\mathbf{4 4}$ into $45 \mathrm{a}-\mathrm{c}$ applying reaction conditions known for similar transformations such as 1.1 equiv. of dicyclohexylcarbodiimide, the corresponding acid $\mathrm{R}^{1} \mathrm{COOH}\left(\mathrm{R}^{1}\right.$ : Me, Et, $\left.\mathrm{Ph}\right)$ and $\mathrm{N}, \mathrm{N}$-dimethylaminopyridine (DMAP) in $\mathrm{CH}_{2} \mathrm{Cl}_{2}$. Under these reaction conditions only very low yields $(<10 \%)$ of compounds 45a $-\mathbf{c}$ could be obtained. In addition, it turned out that the separation of $\mathbf{4 5 a} \mathbf{a}-\mathbf{c}$ from unreacted $\mathbf{4 4}$ was very difficult. After screening several reaction conditions in parallel format it was found that reaction of 44 with 2.5 equiv. of the corresponding $\mathrm{R}^{1} \mathrm{COX}\left(\mathrm{X}=\mathrm{Cl}\right.$ or $\left.\mathrm{R}^{1} \mathrm{CO}_{2}\right)$ in a mixture of DIEA and DMAP in $\mathrm{CH}_{2} \mathrm{Cl}_{2}$ gave good yields of the corresponding compounds 46a-c, which could be easily purified. We believe that the impressive improvement of the yields is based on the fact that the intermediate products $45 \mathbf{a}-\mathbf{c}$ are immediately acylated by the excess of reagent under the reaction conditions to form irreversibly 46a-c. These products were obtained as mixtures of $(E)$ - and $(Z)$-isomers. It turned out that compounds $46 \mathrm{a}\left(\mathrm{R}^{2}=\mathrm{Me}\right)$ and $46 \mathrm{~b}$ $\left(\mathrm{R}^{2}=\mathrm{Et}\right)$ were not stable enough for the subsequent transformations and had to be transacylated into derivatives $47 \mathbf{a}$ and 47b using pivaloyl chloride and $\mathrm{NaCN}$ or 


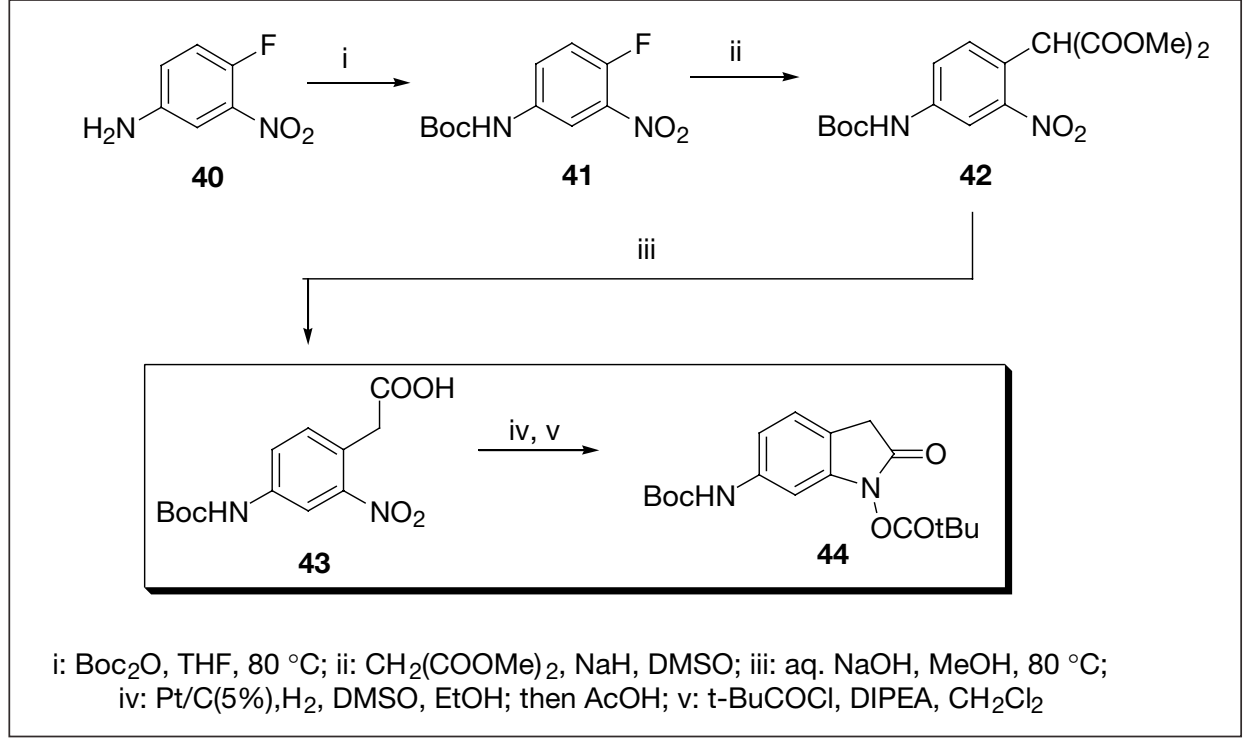

Scheme 7

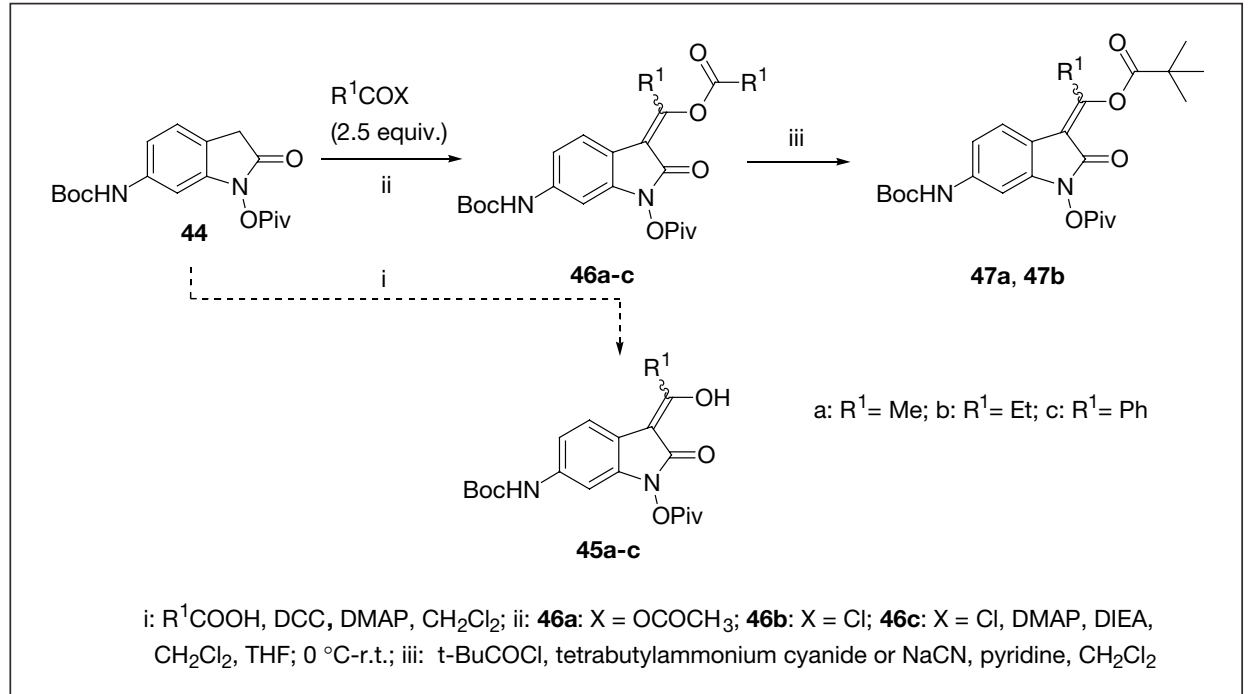

Scheme 8

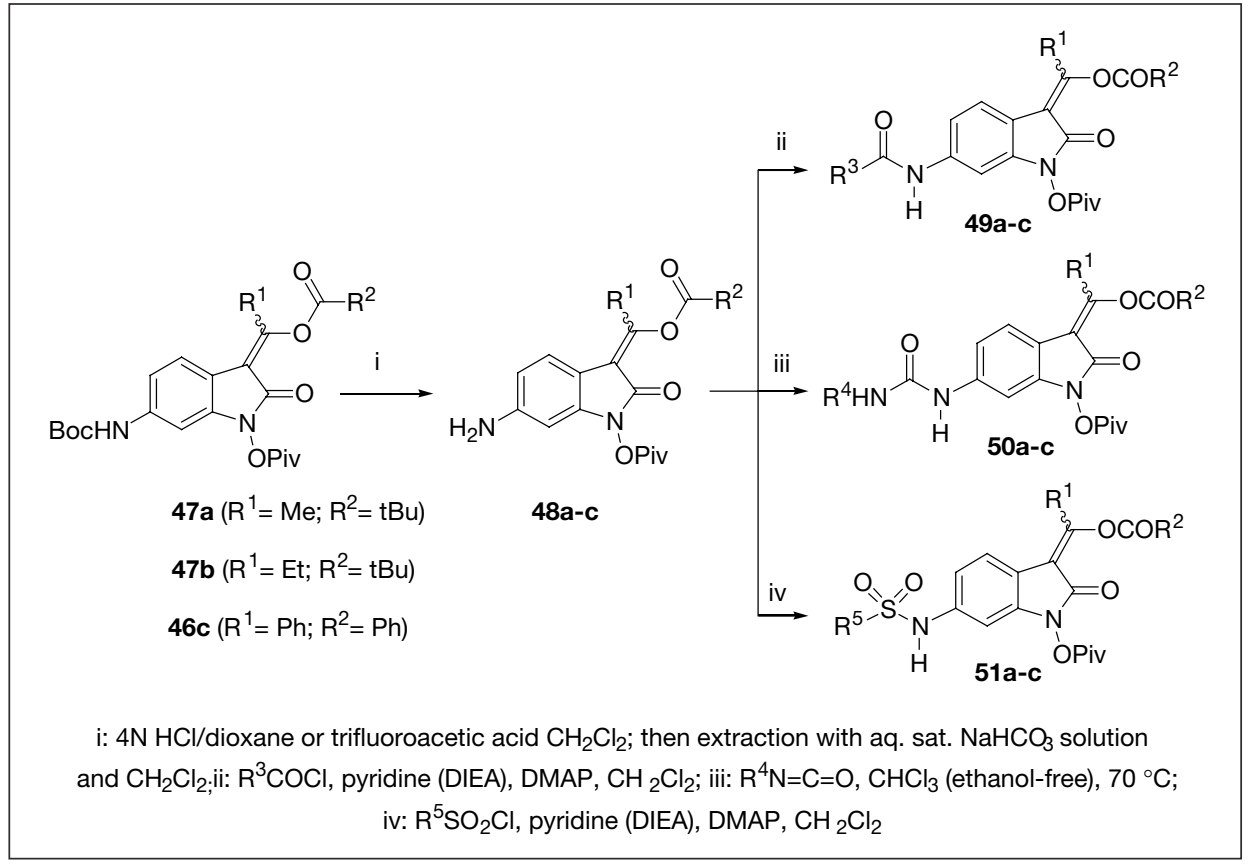

Scheme 9. tetrabutylammonium cyanide in a mixture of pyridine and $\mathrm{CH}_{2} \mathrm{Cl}_{2}$. In contrast $46 \mathrm{c}$ $\left(\mathrm{R}^{2}=\mathrm{Ph}\right)$ was stable enough for the subsequent transformations.

Cleavage of the Boc-group of $46 \mathbf{c}, 47 \mathbf{a}$ and $47 \mathrm{~b}$ was performed with $4 \mathrm{~N} \mathrm{HCl} /$ dioxane or with trifluoroacetic acid in $\mathrm{CH}_{2} \mathrm{Cl}_{2}$, followed by extraction under basic conditions to yield the building blocks $48 \mathbf{a}-\mathbf{c}$ as shown in Scheme 9. Building blocks 48a-c constituted the key precursors for the parallel synthesis of the three sub-libraries 49a-c, 50a-c and 51a-c and were synthesized on a $5 \mathrm{~g}$ scale.

The parallel syntheses of the three sublibraries (anilides 49a-c, ureas 50a-c and sulfonamides 51a-c) were performed under standard conditions (see Scheme 9) and the products were purified by parallel flash chromatography on $\mathrm{SiO}_{2}$. At that stage we aimed at having $100 \mathrm{mg}$ of each of the intermediates.

The final deprotection of products 49a-c, 50a-c and 51a-c into the corresponding final products $\mathbf{5 2 a}-\mathbf{c}, \mathbf{5 3} \mathbf{a}-\mathbf{c}$ and $\mathbf{5 4 a}-\mathbf{c}$ again proved challenging and the solution is described in Scheme 10. As the final products were expected to be highly polar and difficult to purify by chromatography we used N,N-dimethylaminoethyl amine or N,N-dimethylamino-propyl amine in $\mathrm{CHCl}_{3}$ or $\mathrm{CH}_{2} \mathrm{Cl}_{2}$ as deacylating agent yielding the corresponding acylated by-products (Scheme 10) which were soluble in aqueous $\mathrm{HCl}$ solution, whereas the products $52 \mathbf{a}-\mathbf{c}, \mathbf{5 3} \mathbf{a}-\mathbf{c}$ and $\mathbf{5 4 a}-\mathbf{c}$ were soluble in $\mathrm{CHCl}_{3}$ or $\mathrm{CH}_{2} \mathrm{Cl}_{2}$. After evaporation of the solvent the products could be generally obtained in pure form as solids by precipitation from mixtures of ethylacetate/hexane or by purification on reverse phase preparative HPLC. Using this protocol we were able to deliver 131 compounds in quantities between 6-71 $\mathrm{mg}$ and purities of $75-99 \%$ to Roche for biological testing. This program was performed within four months.

\subsection{Biological Results}

From 131 compounds tested, 26 compounds inhibited influenza endonuclease with an $\mathrm{IC}_{50}<50 \mu \mathrm{M}$. More importantly, 10 compounds (e.g. 55, 56, and 57) showed a significant antiviral activity in cell cultures as shown in Fig. 10. The most interesting compound of this first series of compounds was 57 having an $\mathrm{EC}_{50}$ of $6 \mu \mathrm{M}$.

In summary we have developed a new approach to N-hydroxy-indolin-2-one derivatives of type VIII amenable to parallel synthesis and within four months three interesting novel lead compounds (55-57) were generated from a library of $131 \mathrm{com}-$ pounds showing significant antiviral activ- 


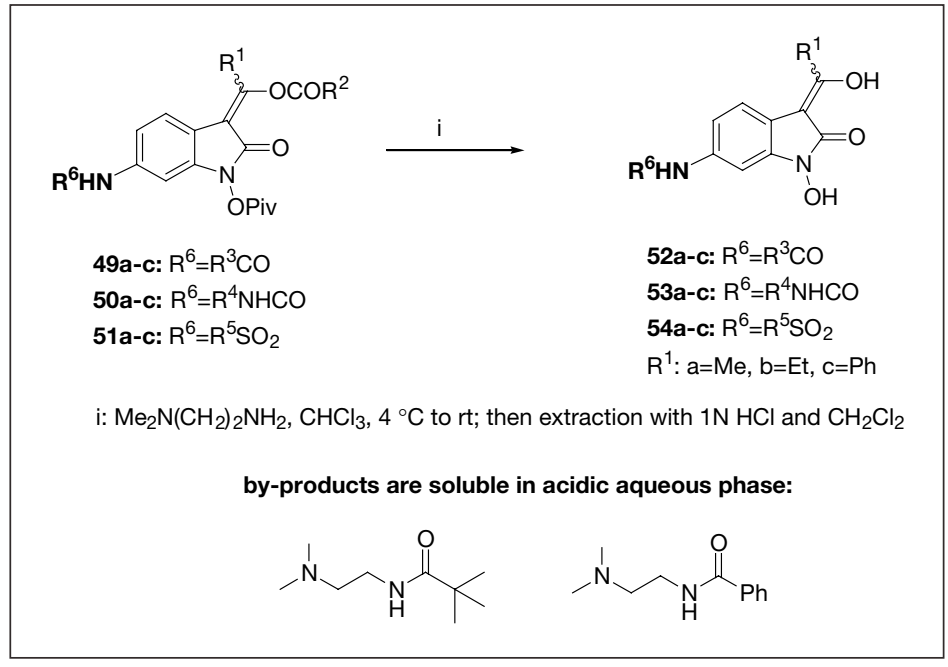

Scheme 10.<smiles>CC(O)=C1C(=O)N(O)c2cc(NC(=O)c3ccc4ccccc4c3)ccc21</smiles>

55

$\mathrm{IC}_{50}=9 \mu \mathrm{M} ; \mathrm{EC}_{50}=21 \mu \mathrm{M}$<smiles>O=C(Nc1cccc(C(=O)O)c1)Nc1ccc2c(c1)N(O)C(=O)C2=C(O)c1ccccc1</smiles>

$\mathrm{IC}_{50}=3 \mu \mathrm{M} ; \mathrm{EC}_{50}=6 \mu \mathrm{M}$

compounds show antiviral activity in cell cultures

Fig. 10. Most active library members

ity in whole cells. Based on our synthetic approach optimization of this lead series should prove straightforward.

This example demonstrates that parallel synthesis approaches can also be successfully applied to highly complex and synthetically challenging compound libraries.

\section{Summary and Outlook}

Parallel synthesis of focused compound libraries for hit confirmation and lead optimization are certainly important drivers for shortening the lead discovery phase in the pharmaceutical and crop protection industries. We have shown three examples in this area which differ significantly in the synthetic strategies which were employed as well as in the chemical complexity of the final products. Nevertheless some general conclusions can be made:

- All three projects were completed within four months. The time invested per compound was significantly reduced by switching from parallel flash chromatography to the highly efficient (unattended) high-throughput preparative HPLC-system, operating on normal and reversed phase.

- Positive screening results were obtained from all three projects

- In general, 100 to 200 compounds per library were synthesized and purified in average amounts of $25 \mathrm{mg}$ per compound in average purities of $90 \%$ (analysed by HPLC).

- Multigeneration and sequential multicomponent reactions are well suited for parallel synthesis as they take ad- vantage of common intermediates and common reactive building blocks and thus lower the overall synthetic effort and cost by significantly reducing the number of steps per final compound.

- Parallel approaches can also be successfully applied for synthesizing highly complex products derived from advanced building blocks obtained by multi-step synthesis. In these cases the parallel steps are preferably performed at the very end of the synthesis as shown in section 4 .

\section{Acknowledgements}

The authors would like to thank the following collaborators from Polyphor: Drs. M. Billet, W. Ganci, P. Jeger, F. Lach, C. Ludin, A. Luther, T. Maetzke, K. Sekanina, and Ms. F. Abdennour, C. Abrecht, Y. Bänninger, C. Barth, A. Bickel, D. Dändliker, S. Dillinger, M. Fischesser, A. Gomez, L. Kiefer, B. Maret, M. Müller, O. Roger, A. Ruetsch, A. Salomon, M. Schneckenburger, K. Steinmetz; and Mrs H. Behra, L. Cornu, N. Desjonqueres, S. Gable, J.-F. Gosalbes, S. Luisoli, and F. Tritsch. Furthermore we would like to thank Sir Jack Baldwin, FRS (University of Oxford, UK), Prof. Dr. J.A. Robinson (University of Zürich) and Prof. Dr. A. Vasella (ETH, Zürich) for stimulating discussions and valuable advice.

Received: February 14, 2003

[1] P. Ermert, D. Obrecht, J.-P. Obrecht, K. Sekanina, Chimia 2000, 54, 198-202.

[2] R.E. Dolle, K.H. Nelson, Jr., J. Comb. Chem. 2002, 4, 369-418; D. Obrecht, J.-M. Villalgordo, 'Solid-Supported Combinatorial and Parallel Synthesis of SmallMolecular-Weight Compound Libraries', Tetrahedron Organic Series, Vol 17, Pergamon, 1998; K. Frobel, T. Krämer, Chemie in unserer Zeit 1996, 30, 270-285.

[3] C. Abrecht, P. Ermert, P. Jeger, D. Obrecht, A. Jeanguenat, S. Farooq, 10th IUPAC International Congress of the Chemistry of Crop Protection, Basel, 2002, Poster 6 (abstract 3a.06).

[4] W.W. Paudler, T.-K. Chen, J. Heterocycl. Chem. 1970, 7, 767.

[5] H. Yamanaka, Heterocycles 1989, 29, 2249.

[6] C. Abrecht, P. Ermert, D. Obrecht, E. Hillesheim, T. Pitterna, P. Maienfisch, 10th IUPAC International Congress of the Chemistry of Crop Protection, Basel, 2002, Poster 34 (abstract 3a.34).

[7] D. Obrecht, P. Ermert, Fifth International Electronic Conference on Synthetic Organic Chemistry (ECSOC-5); www. mdpi.org/ecsoc-5/, September 1-30, 2001, [B0005]

[8] P. Ermert, J. Fässler, K. Klumpp, J.A. Martin, J.H. Merrett, D. Obrecht, K.E.B. Parkes, J. Med. Chem. accepted for publication, 2003.

[9] Presented in part at JCCF14 (Japan Combinatorial Chemistry Focus Group) on April 22nd, 2002, Osaka, Japan.

[10] A. Kende, Synth. Commun. 1990, 20, 2133-38. 